\title{
Formation and densification of mullite through solid-oxide reaction technique using commercial-grade raw materials
}

\author{
RITWIK SARKAR* and MANISH MALLICK \\ Department of Ceramic Engineering, National Institute of Technology, Rourkela 769008, India \\ *Author for correspondence (ritwiksarkar@ rediffmail.com)
}

MS received 15 June 2016; accepted 10 August 2017; published online 5 February 2018

\begin{abstract}
Two different commercially available sources of alumina and silica were used to study the formation and densification behaviour of mullite prepared by solid-oxide reaction technique in a single firing. Phase analysis and densification studies were carried out on the samples sintered between 1200 and $1600^{\circ} \mathrm{C}$. Effect of addition of $1-6 \mathrm{wt} \% \mathrm{MgO}$ on the sintered mullite ceramics was also studied. $\mathrm{MgO}$ was found to improve the density values for all the compositions till $4 \mathrm{wt} \%$ and with higher addition it deteriorated, mainly due to higher extent of liquid phase formation. Mullite formation was found to start below $1200^{\circ} \mathrm{C}$ and constituent oxides were found even at $1600^{\circ} \mathrm{C}$; however, addition of $4 \mathrm{wt} \% \mathrm{MgO}$ was found to complete the mullite formation at $1600^{\circ} \mathrm{C}$ for all the compositions. Microstructural studies showed grain growth in the compositions containing $\mathrm{MgO}$ and higher impurities due to formation of greater extent of liquid phase.
\end{abstract}

Keywords. Mullite; raw materials; $\mathrm{MgO}$ additive; phase analysis; densification; microstructure.

\section{Introduction}

Mullite $\left(3 \mathrm{Al}_{2} \mathrm{O}_{3} \cdot 2 \mathrm{SiO}_{2}\right)$ is the only thermodynamically stable compound formed in the alumina-silica binary system, one of the most easily formed, commonly encountered and important mineral useful for various industrial ceramics products $[1,2]$. Mullite is important because of its excellent characteristics, such as high melting point, low thermal expansion, high thermal shock resistance, excellent corrosion resistance (especially against acidic environments), high hot strength, good micro-hardness and creep resistance up to $1300^{\circ} \mathrm{C}$. Due to its high temperature but low pressure formation conditions, mullite occurs very rarely in nature (the only known natural source is the Island of Mull, Scotland). Mullite has gained significant attention as a material for high-temperature structural applications [3] and it is useful as metal fillers, catalyst supports, radiant burner, heat exchanger, hot blast stove, torpedo ladles, etc. [4].

As mullite is not commercially available, it is prepared synthetically. Various sophisticated methods have been used to prepare high-purity mullite ceramics. Mullite was reported to be formed at $1200^{\circ} \mathrm{C}$ by sol-gel method using aluminium nitrate and tetraethyl orthosilicate [5]. High-strength mullite ceramics were reported to be prepared by spray pyrolysis method using aluminium nitrate and tetraethoxysilane via sintering at $1400^{\circ} \mathrm{C}[6]$. Sintered mullite was reported to be developed by hydrolysis method using aluminium isopropoxide and tetraethoxysilane and firing between 1000 and $1300^{\circ} \mathrm{C}$ [7]. These chemical synthesis routes use high-purity precursor materials and have molecular level mixing during processing, thus resulting in a low-temperature formation of single-phase mullite. However, as these methods require costly chemical ingredients and products are only in limited amounts, they are not commercially successful.

Solid-state reaction technique using commercially available materials is the process for making mullite of commercial importance. Commercially available thermodynamically unstable alumina-silicates $\left(\mathrm{Al}_{2} \mathrm{O}_{3} \cdot \mathrm{SiO}_{2}\right)$, namely, sillimanite, kyanite and andalusite, are widely used for the bulk mullite production. Solid-state sintering of materials bearing $\mathrm{Al}_{2} \mathrm{O}_{3}$ and $\mathrm{SiO}_{2}$ is a low-cost method for mullite formation, which is also used commercially. However, formation through solidoxide reaction is associated with a volume expansion, as higher density alumina (present around 72\%) is converted to lower density mullite phase, and hence it is difficult to obtain good-density mullite in a single firing. The temperature and rate of mullite formation depend on the starting material, particularly on the $\mathrm{Al}_{2} \mathrm{O}_{3}$ and $\mathrm{SiO}_{2}$ reactants used, their chemical purity and particle size distribution [8-13]. The common reactants containing $\mathrm{Al}_{2} \mathrm{O}_{3}$ and $\mathrm{SiO}_{2}$ used for mullite synthesis are commercially available alumina and silica powders, refractory grade bauxite, clay, gibbsite and, in a few cases, sillimanite group of minerals.

Various workers have also worked on the effect of different additives on the mullite formation, its sintering and properties development. The addition of $\mathrm{TiO}_{2}$, up to $4 \mathrm{wt} \%$, was reported [14] to improve the densification behaviour at lower temperatures by the formation of a solid solution with mullite but deteriorated the hot properties at higher temperature by about $25 \%$. The addition of $\mathrm{Y}_{2} \mathrm{O}_{3}$ as sintering aid in clay and reactive alumina-based mullite was reported [15] to enhance density by liquid phase sintering and resulted in equiaxed 
mullite crystals. Addition of $\mathrm{ZrO}_{2}$ was reported [16] to improve the thermal shock resistance property of mullite, and the presence of zirconia particles at the intergranular position of the mullite matrix restricts the grain growth. The addition of $\mathrm{Fe}_{2} \mathrm{O}_{3}$ was found [17] to enhance the densification and grain growth by liquid phase formation and $\mathrm{Fe}_{2} \mathrm{O}_{3}$ enters into the mullite structure by solid solution formation. Also, the presence of $\mathrm{Fe}_{2} \mathrm{O}_{3}$ was found to enhance the strength retainment capacity after initial thermal shock cycles.

Addition of $\mathrm{MgO}$ in mullite ceramics has been studied by many workers mainly as a sintering aid, as mullite has poor sinterability due to poor interdiffusion of $\mathrm{Al}^{3+}$ and $\mathrm{Si}^{4+}$ ions in the mullite lattice structure [18]. Mostly the research works on addition of $\mathrm{MgO}$ in mullite ceramics are based on clay samples or using prefabricated mullite powders. Viswabhaskaran et al $[15,19,20]$ reported that $\mathrm{MgO}$ up to $3 \mathrm{wt} \%$ enhances the densification in mullite samples prepared from clay-based materials. However, further higher amount of $\mathrm{MgO}$ was reported to reduce the density values at higher temperatures. Diffusion of $\mathrm{MgO}$ and $\mathrm{SiO}_{2}$ from mullite grains favours the formation of a liquid phase along the grain boundary and thereby densification takes place, but at excess amount, greater presence of low-melting-temperature silicate causes bloating and reduces the density values [21-23]. Also there are some works where $\mathrm{MgO}$ of very low (up to $0.5 \mathrm{wt} \%$ ) concentration was added and high densities of sintered materials were reported. In such studies, mostly pressure-assisted sintering process was applied for non-commercial nanometric scale mullite powders, which favoured the densification $[23,24]$. Also, high density values were obtained due to impurities present in the mullite powder $\left(\mathrm{ZrO}_{2}\right.$ and $\left.\mathrm{TiO}_{2}\right)$ and some synergistic effect of these impurities with the added $\mathrm{MgO}$ on the densification process [25].

Literature provides information on the use of different sources for solid-oxide reaction route of mullite preparation, but it does not provide much information on use of sources like sintered alumina (like tabular alumina), fume silica (FS) or quartz. Also, there is hardly any study on the comparison of the effects of these raw materials for mullite formation and densification prepared under similar processing conditions.
Such a work is undertaken in the present study, where two different commercially available alumina sources are used along with two different sources of silica. Also, the effect of the addition of $\mathrm{MgO}$ in such materials of alumina and silica mixture for mullite is not found in the literature and hence it is studied for all the compositions at 1,2, 4 and $6 \mathrm{wt} \%$ level. Single-stage firing technique is used for mullite formation (which is associated with volumetric expansion) and densification purpose in the temperature range of $1200-1600^{\circ} \mathrm{C}$.

\section{Experimental}

Two different alumina sources, namely white tabular alumina (WTA) fines and technical alumina (TA) fines (both supplied by Almatis, India) and two different silica sources, namely FS (Elkem, India) and quartz powder (Q), were used to make the stoichiometric mullite. Physico-chemical properties of the starting raw materials are provided in table 1. Four batches, namely B1 using WTA and FS, B2 using TA and FS, B3 using TA and Q and B4 using WTA and Q, are prepared using these raw materials. The details of the batch compositions of all the batches are shown in table 2, with the purity level of the ingredients. Each batch composition was first wet mixed in a teflon-lined ball mill with alumina balls for $2 \mathrm{~h}$, and later dried at $110^{\circ} \mathrm{C}$. These mixed powders were next mixed with $5 \%$ PVA solution (4\% concentration) used as a green binder. The mixed batches were then uni-axially pressed to pellet shapes (15 mm diameter and $15 \mathrm{~mm}$ height) in a hydraulic press (Model 3887, Carver Inc. USA) at $150 \mathrm{MPa}$ pressure with a holding time of $30 \mathrm{~s}$ at the peak pressure. The green pellets were dried at $110^{\circ} \mathrm{C}$ for 1 day and then sintered at different temperatures, i.e., $1200,1300,1400,1500$ and $1600^{\circ} \mathrm{C}$, at a heating rate of $2{ }^{\circ} \mathrm{C} \mathrm{min}^{-1}$ with a dwelling time of $2 \mathrm{~h}$ at the peak temperatures.

Sintered pellets were characterized for densification, phase analysis and microstructural studies. Densification studies were conducted by the conventional liquid displacement method according to the Archimedes principle using the boiling water method. Phase identification was performed using

Table 1. Physico-chemical properties of the raw materials.

\begin{tabular}{lcccr}
\hline Properties & WTA & TA & FS & Q \\
\hline $\mathrm{SiO}_{2}$ & 0.1 & 0.1 & 97.7 & 98.1 \\
$\mathrm{Al}_{2} \mathrm{O}_{3}$ & 99.1 & 99.5 & 0.3 & 0.7 \\
$\mathrm{Fe}_{2} \mathrm{O}_{3}$ & 0.1 & 0.1 & 0.2 & 0.7 \\
$\mathrm{TiO}_{2}$ & & & 0.2 & 0.1 \\
$\mathrm{CaO}$ & 0.1 & & 0.1 & 0.1 \\
$\mathrm{MgO}$ & 0.4 & 0.2 & 0.3 & 0.2 \\
$\mathrm{Na}_{2} \mathrm{O}+\mathrm{K}_{2} \mathrm{O}$ & & & 0.9 & $95 \%<45 \mu \mathrm{m}$ \\
$\mathrm{Loss}$ on ignition & $98 \%<45 \mu \mathrm{m}$ & $D_{50}=2.9 \mu \mathrm{m}$ & $D_{50}=0.5 \mu \mathrm{m}$ & $95 \%$ \\
Particle size & $98 \%$ &
\end{tabular}


Table 2. Details of the batch compositions (in wt $\%$ ).

\begin{tabular}{lcccc}
\hline Batch & B1 & B2 & B3 & B4 \\
\hline WTA & 71.55 & & & 71.62 \\
TA & & 71.46 & 71.54 & \\
FS & 28.45 & 28.54 & & \\
Q & & & 28.46 & 28.38 \\
\hline
\end{tabular}

an X-ray diffractometer (Rigaku multipurpose Ultima X-Ray Diffractometer, Japan) with $\mathrm{CuK} \alpha$ radiation at a scanning speed of $2^{\circ} \mathrm{min}^{-1}$. Microstructural study of the sintered surface of the batch samples, without and with $\mathrm{MgO}$, sintered at $1600^{\circ} \mathrm{C}$ was performed using a field emission scanning electron microscope (FESEM, model Nova Nano SEM, FEI, US make) after $240 \mathrm{~s}$ of gold coating in a sputter coater. Effect of addition of $\mathrm{MgO}$ at 1, 2, 4 and $6 \mathrm{wt} \%$ level on the densification of all the batch materials was also studied at sintering temperature of $1600^{\circ} \mathrm{C}$. Again, the effect of $\mathrm{MgO}$ on phase formation and microstructural development of all the batches was studied for $4 \mathrm{wt} \% \mathrm{MgO}$ addition. Average size of the grains in the microstructural photograph was calculated as per the linear intercept method [26].

\section{Results and discussion}

Table 1 shows that alumina sources used for the study are $>99 \%$ pure but silica sources are relatively less pure. Also, TA and FS are much finer compared with WTA and Q sources. Again, quartz powder, though it contains a higher amount of silica compared with FS, is less pure as it contains a higher amount of impurities like $\mathrm{Al}_{2} \mathrm{O}_{3}$ and $\mathrm{Fe}_{2} \mathrm{O}_{3}$. FS has a higher value of loss on ignition, which may be associated with the presence of free carbon coming from its manufacturing process and is purer than quartz when fired.

\subsection{Phase analysis study}

Details of the phase analysis study, using the X-ray diffraction (XRD) plots of batches B1, B2, B3 and B4 are shown in figures $1,2,3$ and 4 , respectively. The nature of phase evolution with temperature and $\mathrm{MgO}$ addition is very similar in all the batches. However, there are some differences in the peak heights of the final phases present in the sintered samples prepared from different sources of raw materials, which may be due to the effect of the raw materials fineness, impurities present, etc. However, the overall trend of phase evolution and phase compositions in the sintered materials are exactly similar. Materials fired at $1200^{\circ} \mathrm{C}$ showed the initiation of mullite phase formation but the major peaks obtained are for alumina and silica. When the temperature is increased to $1600^{\circ} \mathrm{C}$, mullite is the major phase along with the reactant phases. From samples fired at $1600^{\circ} \mathrm{C}$, it is confirmed that the mullite formation is not completed even at this temperature.

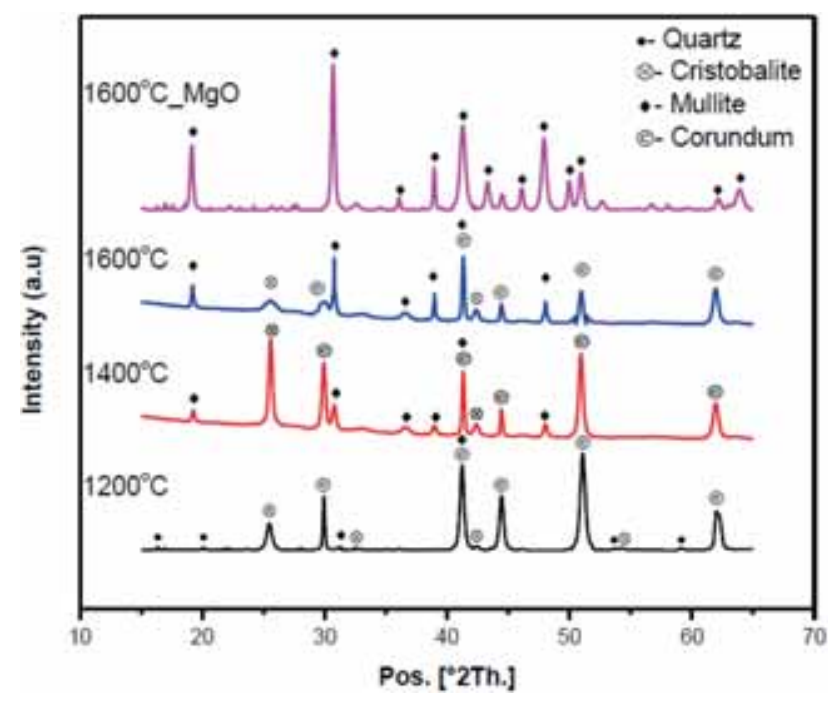

Figure 1. Phase analysis study of B1 batch.

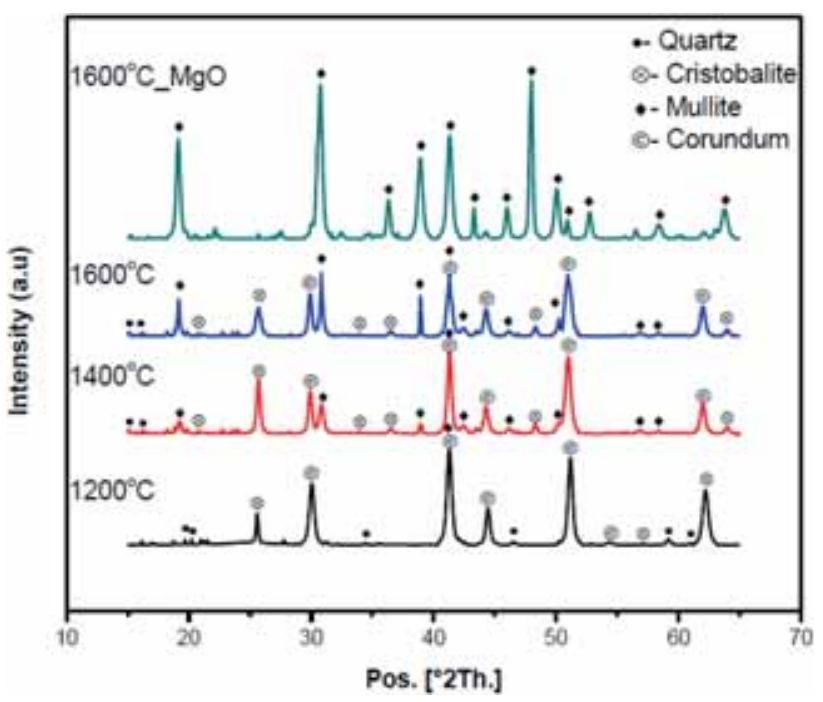

Figure 2. Phase analysis study of B2 batch.

This indicates that though the mullite formation from its constituent oxides starts below $1200^{\circ} \mathrm{C}$, it is not completed even on firing at $1600^{\circ} \mathrm{C}$; thus, the mullite formation reaction is slow in nature.

However, the addition of $\mathrm{MgO}$ was found to strongly enhance the mullite phase formation in all the compositions. All the peaks of the reactant phases present in different batches after sintering at $1600^{\circ} \mathrm{C}$ are absent on addition of $4 \mathrm{wt} \% \mathrm{MgO}$ and only mullite phase was obtained. This indicates that mullite formation is enhanced by $\mathrm{MgO}$ addition, as also found by different workers [23,27] and only mullite phase is reported on sintering at $1600^{\circ} \mathrm{C}$ [27]. Increase in lattice diffusion in the presence of $\mathrm{MgO}$ was reported as the reason for such enhancement in mullite formation [18]. 


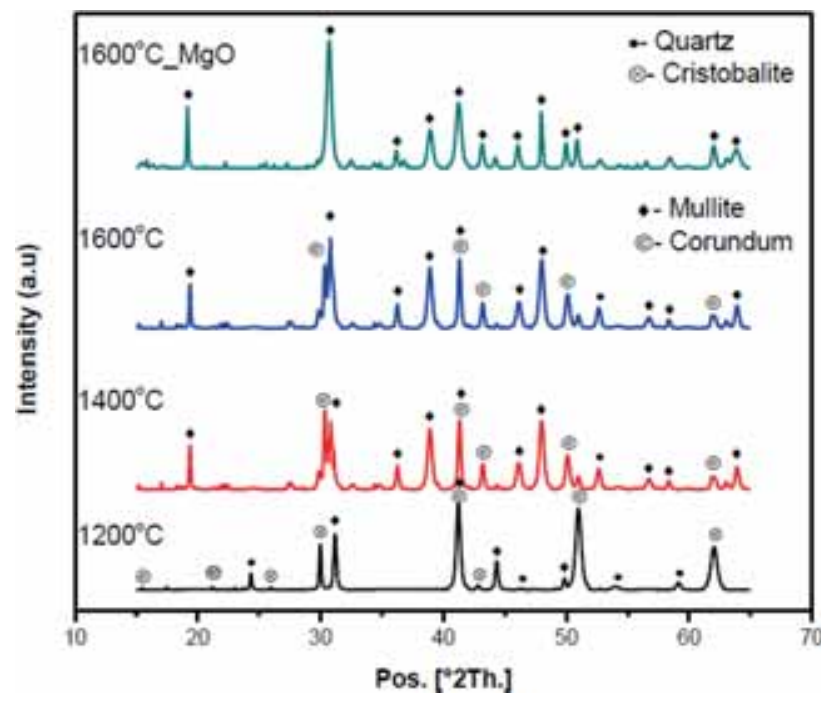

Figure 3. Phase analysis study of B3 batch.

\subsection{Densification study}

Increase in density values with the increase in sintering temperature is observed (figure 5) for all the batches due to greater sintering at higher temperatures. However, the density values are found to enhance sharply for the B3 and B4 batches, especially at and above $1500^{\circ} \mathrm{C}$. This may be due to the presence of quartz in these compositions, which contains a higher amount of impurities that help densify the materials through liquid-phase formation. However, hardly any effect on the density values of sintered material was found from the variation in alumina quality. Impurities like $\mathrm{Fe}_{2} \mathrm{O}_{3}$ and alkalis (like $\mathrm{Na}_{2} \mathrm{O}$ and $\mathrm{K}_{2} \mathrm{O}$ ) react with the constituent oxides $\mathrm{Al}_{2} \mathrm{O}_{3}$ and $\mathrm{SiO}_{2}$ and form liquid phases in

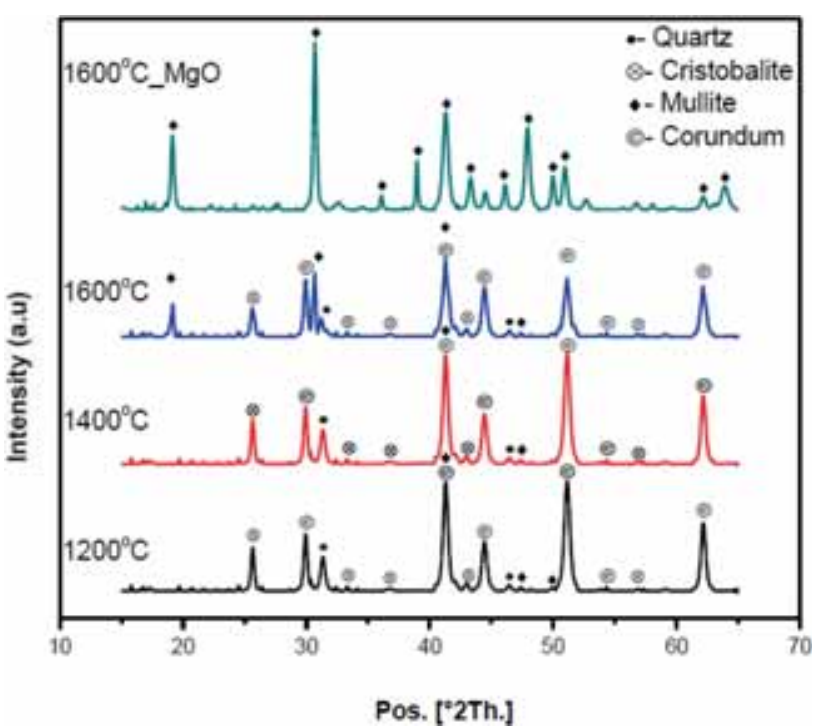

Figure 4. Phase analysis study of B4 batch.

$\mathrm{Al}_{2} \mathrm{O}_{3}-\mathrm{SiO}_{2}-\mathrm{Fe}_{2} \mathrm{O}_{3}, \mathrm{Al}_{2} \mathrm{O}_{3}-\mathrm{SiO}_{2}-\mathrm{Na}_{2} \mathrm{O} / \mathrm{K}_{2} \mathrm{O}$ and $\mathrm{Al}_{2} \mathrm{O}_{3}-$ $\mathrm{SiO}_{2}-\mathrm{Fe}_{2} \mathrm{O}_{3}-\mathrm{Na}_{2} \mathrm{O} / \mathrm{K}_{2} \mathrm{O}$ systems, leading to liquid-phase sintering, and results in greater densification.

Introduction of $\mathrm{MgO}$ was found to enhance the density values for all the batches (figure 6) sintered at $1600^{\circ} \mathrm{C}$. Increase in $\mathrm{MgO}$ content from 1 to $4 \mathrm{wt} \%$ was found to increase the density values gradually and continuously. Again, for the B3 and B4 batches, density values were higher. The corresponding apparent porosity values (figure 7) were also found to be reduced greatly and for B3 and B4 batches, the porosity values were minimum. This enhancement in densification of the mullite batches in the presence of $\mathrm{MgO}$ is also reported by many workers $[16,23,25,27]$. The main reason for such enhancement in densification is reported to be liquid-phase

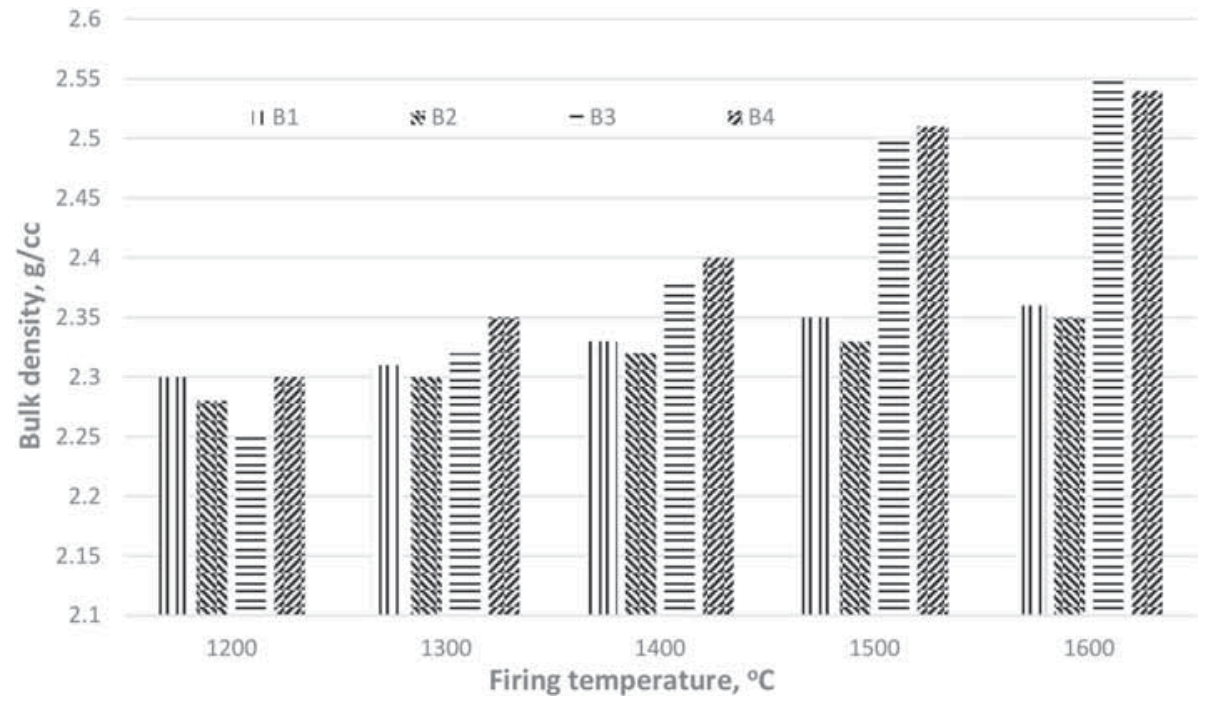

Figure 5. Bulk density values of the batches sintered at different temperatures without $\mathrm{MgO}$. 


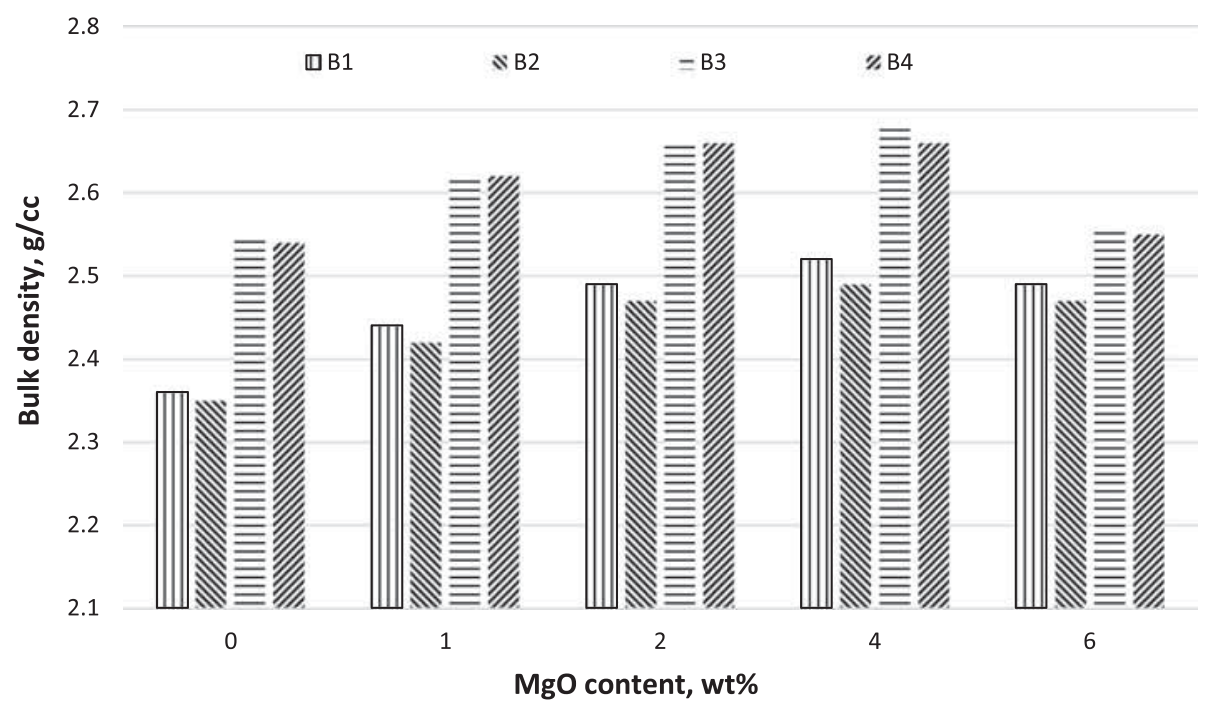

Figure 6. Bulk density values of the batches sintered at $1600^{\circ} \mathrm{C}$ containing $4 \mathrm{wt} \% \mathrm{MgO}$.

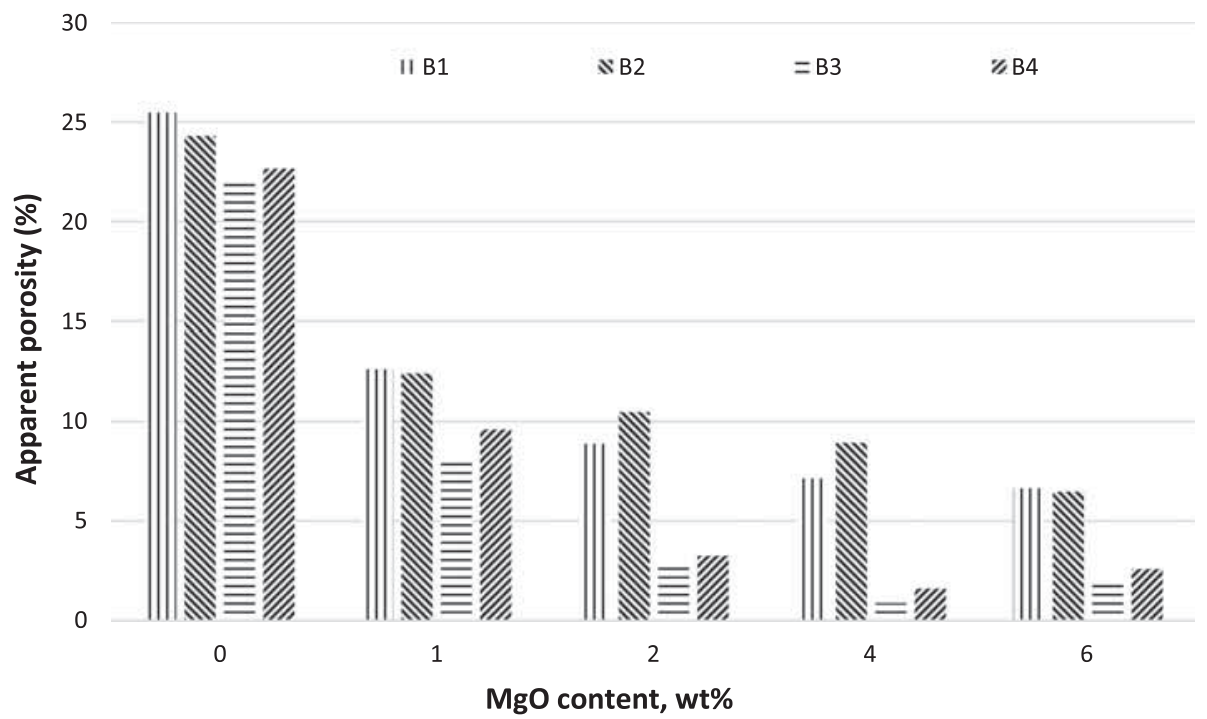

Figure 7. Apparent porosity values of the batches sintered at $1600^{\circ} \mathrm{C}$ containing $4 \mathrm{wt} \% \mathrm{MgO}$.

formation in the $\mathrm{Al}_{2} \mathrm{O}_{3}-\mathrm{SiO}_{2}-\mathrm{MgO}$ system [16,25]. This liquid helps enhance the grain sizes, reduces the pore volume and results in improved density values [16]; also greater lattice diffusion in presence of $\mathrm{MgO}$ [16] was reported to be a reason for enhanced density values. Quartz containing B3 and $\mathrm{B} 4$ batches have the greater extent of impurity content, namely $\mathrm{Fe}_{2} \mathrm{O}_{3}, \mathrm{CaO}$ and alkalis. Thus, the formation of the liquid phase in these batches is higher, resulting in a greater extent of liquid phase sintering and densification.

However, with further increase in $\mathrm{MgO}$ content to $6 \mathrm{wt} \%$, the density values for all the batches were found to decrease. The degradation was found to be marginal for the B1 and B2 batches and prominent for B3 an B4 batches. The degradation may be due to the excessive amount of liquid phase formation at higher temperature in the presence of $\mathrm{MgO}$ in the $\mathrm{Al}_{2} \mathrm{O}_{3}-\mathrm{SiO}_{2}-\mathrm{MgO}$ system, as also mentioned in earlier reports [21-23]. However, in $\mathrm{B} 3$ and $\mathrm{B} 4$ batches, due to the presence of higher amount of impurities, namely $\mathrm{Fe}_{2} \mathrm{O}_{3}, \mathrm{CaO}$ and $\mathrm{Na}_{2} \mathrm{O} / \mathrm{K}_{2} \mathrm{O}$, coming from the constituent quartz, much greater amount of liquid phases (in the systems from multicomponent oxides (containing $\mathrm{Al}_{2} \mathrm{O}_{3}-\mathrm{SiO}_{2}-\mathrm{MgO}-\mathrm{Fe}_{2} \mathrm{O}_{3}-$ $\mathrm{CaO}-\mathrm{Na}_{2} \mathrm{O} / \mathrm{K}_{2} \mathrm{O}$ ) was formed in the presence of $6 \mathrm{wt} \% \mathrm{MgO}$ in the materials. This excessive liquid may have affected the deterioration in densification strongly.

\subsection{Microstructural analysis}

Microstructural photographs of the sintered surface of samples sintered at $1600^{\circ} \mathrm{C}$ (without $\mathrm{MgO}$ ) show (figure 8) gross variation among the batches $\mathrm{B} 1, \mathrm{~B} 2$ and $\mathrm{B} 3, \mathrm{~B} 4$. Batches 

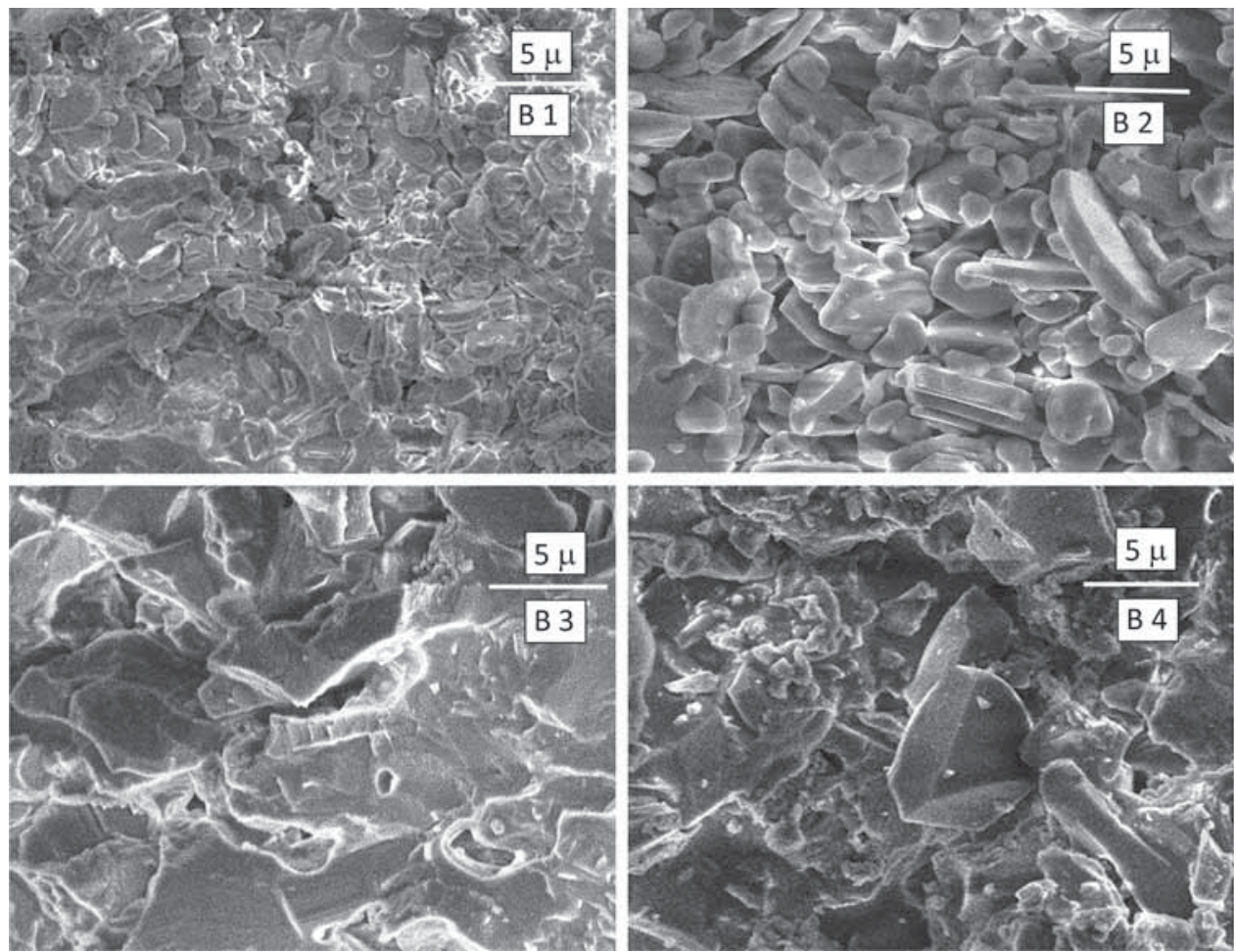

Figure 8. FESEM photographs of different batches sintered at $1600^{\circ} \mathrm{C}$ without $\mathrm{MgO}$.
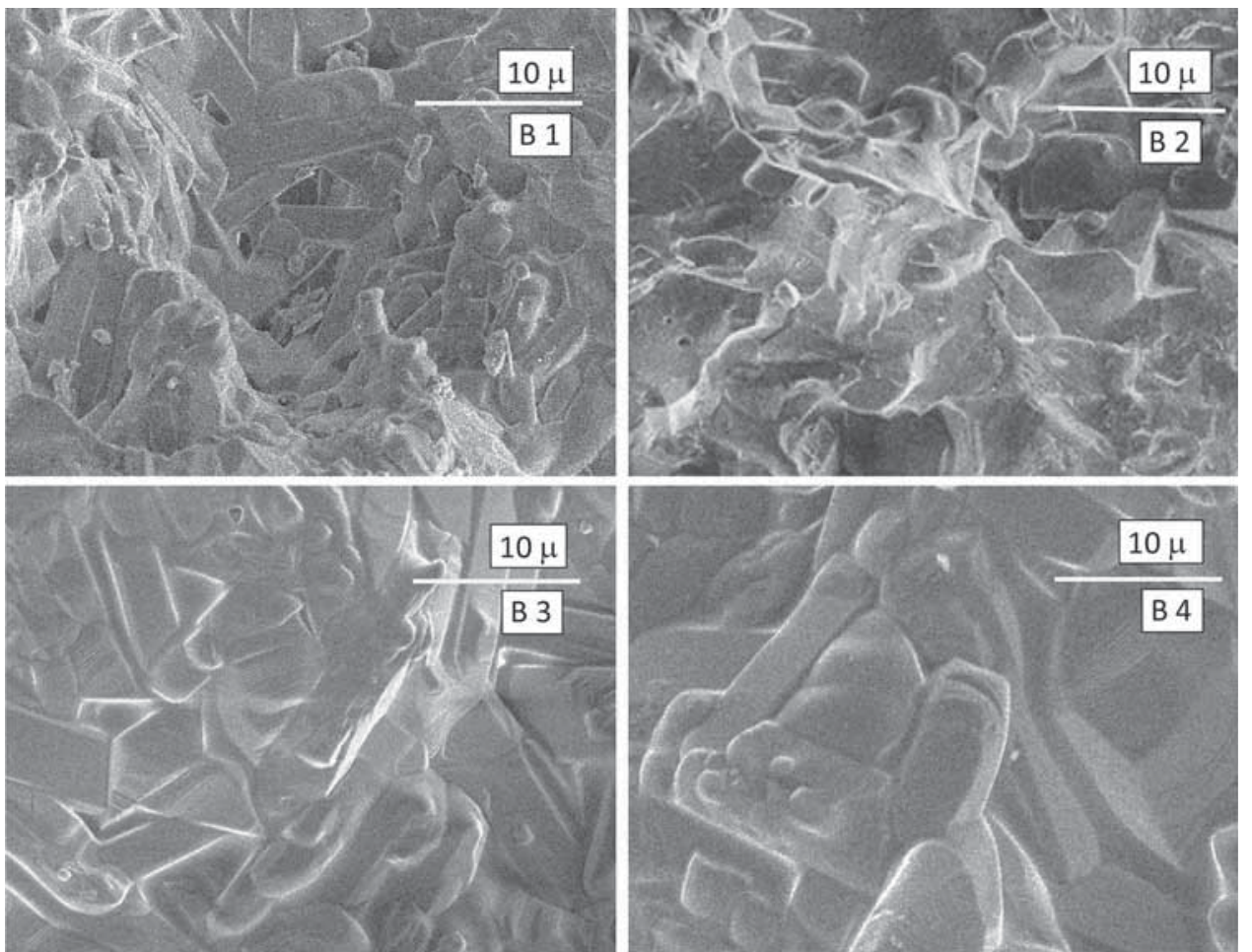

Figure 9. FESEM photographs of different batches sintered at $1600^{\circ} \mathrm{C}$ containing $4 \mathrm{wt} \% \mathrm{MgO}$. 
B1 and B2 show non-uniform sized, platelet-type grains distributed uniformly through the photograph. Intergranular porosity can also be seen in these two batches. The size of the grains in TA-containing B2 batch is found to be higher than that of WTA-containing B1 batch, which may be due to a greater extent of growth occurring from the increased reactivity of the batch due to the finer size of the alumina particles. Batches B3 and B4 show a different microstructural feature. Formation of the liquid phase is evident in these batches with diffused grain boundaries and evidences of viscous flow at the grain boundaries, resulting in a coarser size of the grains. The presence of higher amount of impurities in quartz-containing B3 and B4 batches causes the formation of greater extent of liquid phase.

The addition of $\mathrm{MgO}$ is found (figure 9) to completely change the microstructural characteristics of the batches. An increase in the grain size is observed for all the batches, indicating grain growth in the presence of $\mathrm{MgO}$. This may be due to increased lattice diffusion in the presence of $\mathrm{MgO}$ [16] and formation of the liquid phase in the batches in $\mathrm{Al}_{2} \mathrm{O}_{3}-\mathrm{SiO}_{2}$ $\mathrm{MgO}$ system $[16,23,25,27]$. Batch $\mathrm{B} 1$ shows some elongated plate-like grains with the evidences of liquid phase formations and also some porosity. The elongated mullite grains are about 6-12 $\mu \mathrm{m}$ in length and 2-3 $\mu \mathrm{m}$ in width. The average size of the mullite grains is $3.6 \mu \mathrm{m}$. B2 batch shows non-uniform sized, equiaxed grains without sharp edges and also some large grains with intragranular porosity. The presence of liquid phase is also evident from the photograph. The average size of the mullite grains is $3.9 \mu \mathrm{m}$. B3 and B4 batches show considerably different microstructural features compared with B1 and B2. Larger sized, elongated and equiaxed grains and evidences of viscous flow at the grain boundaries are observed in these batches with diffused grain boundaries. They indicate the formation of greater extent of liquid phase during firing. These growth and coarsening effects in B3 and B4 batches result in some porosity within the granular structure that adversely affects the compaction behaviour, as observed by the decreased density values (figure 6). The average grain sizes of $\mathrm{B} 3$ and $\mathrm{B} 4$ batches are calculated to be 4.8 and $5.3 \mu \mathrm{m}$, respectively.

\section{Conclusions}

(1) Two different commercially available alumina sources, namely WTA and TA fines, and two different silica sources, namely FS and quartz fines, were used to study the formation and densification of mullite through solid-oxide reaction technique.

(2) Mullite formation was found to start below $1200^{\circ} \mathrm{C}$ but not completed even at $1600^{\circ} \mathrm{C}$ for all the compositions. The addition of $\mathrm{MgO}$ was found to enhance the mullite formation and only mullite phase was obtainind at $1600^{\circ} \mathrm{C}$ for all the batches containing $4 \mathrm{wt} \% \mathrm{MgO}$.

(3) Quartz-containing compositions showed increased density values after liquid-phase sintering due to the greater presence of impurities in quartz. The addition of $\mathrm{MgO}$ upto $4 \mathrm{wt} \%$ was found to enhance the densification considerably for all the batches.

(4) Density values of all the batches deteriorated on addition of $6 \mathrm{wt} \% \mathrm{MgO}$ and the deterioration was found to be stronger for quartz-containing B3 and B4 batches due to the presence of greater extent liquid phases formed due to the presence of higher amount of impurities.

(5) This higher amount of liquid phase formation in B3 and B4 batches also caused greater extent of growth of the grains.

\section{Acknowledgement}

We thankfully acknowledge the support of Mr S Mukherjee and $\mathrm{Mr} \mathrm{S}$ Chaterjee of Almatis, India, for the raw materials and the staff of Department of Ceramic Engineering, NIT, Rourkela, for different experiments during the work, especially for the phase analysis and microstructural study.

\section{References}

[1] Torrecillias R, De Aza S, Moya J S, Epicier T and Fantozzi G 1990 J. Mater. Sci. Lett. 91400

[2] Skoog A J and Moore R E 1998 Am. Ceram. Soc. Bull. 671180

[3] Aksay I A, Dabbs D M and Sarlkaya M 1991 J. Am. Ceram. Soc. 742343

[4] Hildmann B and Schneider H 2005 J. Am. Ceram. Soc. 882879

[5] Zhang Y, Ding Y, Gao J and Yang J 2009 J. Eur. Ceram. Soc. 291101

[6] Dabbs D M, Yao N and Aksay I A 1999 J. Nanopart. Res. 1 127

[7] Yoshida K, Hyuga H, Kondo N and Kita H 2010 Mater. Sci. Eng. B 17366

[8] Aksay I A, Dabbs D M and Sarikaya M 1991 J. Am. Ceram. Soc. 742343

[9] Nurishi Y and Pask J A 1982 Ceram. Int. 857

[10] Saruhan B, Albers W, Schneider H and Kaysser W A 1996 J. Eur. Ceram. Soc. 161075

[11] Rana A P S, Aiko O and Pask J A 1982 Ceram. Int. 8151

[12] Rodrigo P D D and Boch P 1985 Int. J. High Technol. Ceram. 13

[13] Boch P, Chartier T and Rodrigo P D D 1990 In: S Somiya, R F Davis and J A Pask (eds) Mullite and mullite matrix composites Ceramic Transactions vol 6 (Westerville, OH: American Ceramic Society) p 353

[14] Tripathi H S and Banerjee G 1998 J. Eur. Ceram. Soc. 182081

[15] Viswabaskaran V, Gnanam F D and Balasubramanian M 2003 J. Mater. Process. Technol. 142275

[16] Tripathi H S, Das S K, Mukherjee B, Ghosh A and Banerjee G 2001 Ceram. Int. 27833

[17] Tripathi H S, Das S K and Banerjee G 2000 Ceram. Int. 261

[18] Lee W E and Rainforth W M 1994 Ceramic microstructures: property control by processing (London: Chapman \& Hall) p 299 
[19] Viswabaskaran V, Gnanam F D and Balasubramanian M 2003 J. Mater. Sci. Lett. 22663

[20] Viswabaskaran V, Gnanam F D and Balasubramanian M 2004 Appl. Clay Sci. 2529

[21] Montanaro L, Esnouf C, Perrot C, Thollet G, Fantozzi G and Negro A 2000 J. Am. Ceram. Soc. 83 189

[22] Montanaro L, Tulliani J M, Perrot C and Negro A 1997 J. Eur. Ceram. Soc. 171715
[23] Ismail M G M U, Tsunatori H and Nakai S 1990 J. Mater. Sci. 252619

[24] Sivakumar R, Jayaseelan D D, Nishikawa T, Honda S and Awaji H 2001 Ceram. Int. 27537

[25] Soutoa P M, Menezesb R R and Kiminami R H G A $2009 \mathrm{~J}$. Mater. Process. Technol. 209548

[26] Wrust J C and Nelson J A 1972 J. Am. Ceram. Soc. 55109

[27] Heraiz M, Merrouche A and Saheb N 2006 Adv. Appl. Ceram.: Struct. Funct. Bioceram. 105285 